\title{
Production of drum-dried jackfruit (Artocarpus heterophyllus) powder with different concentration of soy lecithin and gum arabic
}

\begin{abstract}
The aim of the present study was to determine the optimum concentration of soy lecithin and gum arabic in producing drum-dried jackfruit (Artocarpus heterophyllus) powder using response surface methodology (RSM). Jackfruit puree was dried using a double drum drier set at $1 \mathrm{rpm}$, drum clearance of 0.01 in., and steam pressure of 2.3 bar. Soy lecithin and gum arabic were incorporated into jackfruit puree at different concentrations ranged from $1 \%$ to $5 \%$ and $5 \%$ to $15 \%$, respectively. Soy lecithin and gum arabic were significant factors (at $95 \%$ confidence level) for moisture content, bulk density, Hunter L, a, b values and hedonic test during drum drying of jackfruit. A second-order polynomial model was found for each of the significant response. The jackfruit puree formulation to produce a good quality powder could be obtained by incorporating $2.65 \%$ of soy lecithin and $10.28 \%$ of gum arabic into the jackfruit puree ( $40 \% \mathrm{v} / \mathrm{w}$ water).
\end{abstract}

Keyword: Jackfruit (Artocarpus heterophyllus), Response surface methodology, Drum drying, Soy lecithin, Gum arabic 